\title{
Impact of Knowledge Spillover on Regional Club Convergence in China
}

\author{
Hui Tian ${ }^{1}$, Fei Lei ${ }^{1, *}$, Pudong Huang ${ }^{1}$, Luoyi Huang ${ }^{1}$, Liting Ye ${ }^{1}$, and Jiatian Lai ${ }^{1}$ \\ ${ }^{1}$ GuangdongUniversity of Science and Technology, School of Finance and Economics, Dongguan, China
}

\begin{abstract}
Knowledge spillover theory introduces specialized knowledge and human capital accumulation into the production function, breaks through the limitations of traditional economic theory, and illustrates the continuous and permanent source and power of economic growth. This article attempts to study the "club phenomenon" of the uneven development of China's regional economy from the perspective of knowledge spillover, using the Spatial Dubin Model (SDM) to process China's provincial data from 1991 to 2015. Studies have shown that knowledge spillovers are conducive to narrowing the gap in the level of economic development between the eastern and central regions of China, but the gap in the level of economic development between the two regions is gradually widening, and there is a "club phenomenon". Therefore, developing regional cooperation models and focusing on cultivating talents for innovation can improve China's uneven regional economic development to a certain extent.
\end{abstract}

\section{INTRODUCTION}

As the economic development level of eastern, central and western regions of China continues to grow, the economic gap between regions has always existed ${ }^{[1]}$. Club convergence refers to the conditional convergence within the region with poor economic foundation and the region with high level of economic development, but there is no convergence feature between the two regions ${ }^{[2]}$. In the new growth theory, some scholars believe that the convergence of economic growth is due to the diffusion of technology between regions. The technological level gap between regions and the differences in economic systems will lead to economic gaps between regions ${ }^{[3]}$. A lot of literature research objects are mostly concentrated in developed countries and regions such as Europe and America ${ }^{[4]}$, and there are relatively few literatures that take less developed countries and regions as the research objects of knowledge spillover effects.

In the context of global trade, knowledge and technology have gradually become leading factors in economic development. Industrial transfer in economic activities is often accompanied by the proliferation of technology. This form of knowledge spillover can be imitated and used by underdeveloped regions at a very low cost to increase the economic productivity of the region and promote the economic level. Improvement.

From the perspective of knowledge and technology, this article estimates the effect of knowledge spillover on the phenomenon of regional economic clubs in our country. Theoretically, it is an extension and application of the knowledge production function. In addition, the empirical results of this article can provide some ideas for narrowing the economic gap between the underdeveloped regions and the developed regions, helping the underdeveloped regions to find their own comparative advantages, and gradually narrowing the distance between the economic levels of the developed regions.

\section{MATERIALS AND METHODS}

This article aims to study the impact of knowledge spillovers on the coordinated development of China's regional economy. On the basis of collating relevant literature on regional economic growth and economic convergence, we use the knowledge stock and per capita GDP of China's three major economic regions from 1991 to 2015 to conduct statistical research on absolute gaps and space. This paper uses the perpetual inventory method to calculate the R\&D knowledge stock ${ }^{[5]}$. At the same time, in order to reduce the distortion of data caused by the interference of price factors on per capita GDP, 1991 was used as the base period to calculate the actual per capita GDP of each province and city.

The Theil index will not be disturbed by the number of units in the space, it is convenient to compare the economic convergence trends within each region, and is suitable for decomposition and comparison of multi-level spatial structures. Therefore, the Theil index is used to test the club convergence phenomenon in this paper. The calculation formula is:

$$
T_{t}=\sum_{i} \sum_{j}\left[\frac{Y_{i j t}}{Y_{t}}\right] \ln \left[\frac{Y_{j i t}}{\frac{Y_{t}}{N_{i j t}}}\right]
$$

\footnotetext{
* Corresponding author:2745776452@qq.com.
} 
$Y_{i j}$ is the GDP of the $j$ th economy in area $\mathrm{i}, N_{i j}$ is the population of the $j$ th economy in area $i$, and $Y$ and $N$ represent the total GDP and the total population.

Testing the correlation between spatial variables is a prerequisite for using spatial econometric models. In this paper, the general adjacency weight matrix is added to the local Moran's I model. Local Moran's I is also called the generalized Moran index, which is used to analyze the degree of agglomeration of spatial sample data. The index calculation formula is as follows:

$$
\mathrm{I}=\frac{x_{i}-\bar{x}}{S^{2}} \sum_{j \neq i} w_{i j}\left(x_{j}-\bar{x}\right)
$$

$x$ is the observation value, $w_{i, j}$ is the spatial weight matrix, $S^{2}$ is the variance, when $I_{i}$ is a positive number, it means that the attribute value of a neighboring area is similar, and when $I_{i}$ is a negative number, it means that a spatial unit is adjacent to The attribute values of the cells are not similar.

Finally, on the basis of Barro and Sala-I-Martin and Islam, $\mathrm{Yu}$ and Lee considered a labor-enhancing CobbDouglas production function:

$$
Y_{i, t}=K_{i, t}^{\alpha}\left(A_{i, t} L_{i, t}\right)^{1-\alpha},(0<\alpha<1)
$$

In this paper, the spatial Dubin model (SDM) is selected to estimate the spatial dynamic panel model, and the formula for estimating the spatial dynamic panel is derived as follows:

$$
\begin{aligned}
& \ln y_{i, t}=\alpha+\lambda \sum_{j \neq i}^{n} w_{i, j} \ln y_{j, t}+\beta \ln y_{i, t-1}+\delta \ln X_{i, t}+ \\
& \rho \sum_{j \neq i}^{n} w_{i, j} \ln y_{j, t-1}+\eta \sum_{j \neq i}^{n} w_{i, j} \ln X_{i, t}+\mu_{i}+\varepsilon_{i, t}
\end{aligned}
$$

This paper uses this model to estimate the three typical regions of East, Central and West respectively, which can better explain the influence of knowledge spillover in the convergence process of regional economic clubs.

\section{RESULTS \& DISCUSSION}

\subsection{The spatial evolution trend of knowledge stock and per capita GDP growth}

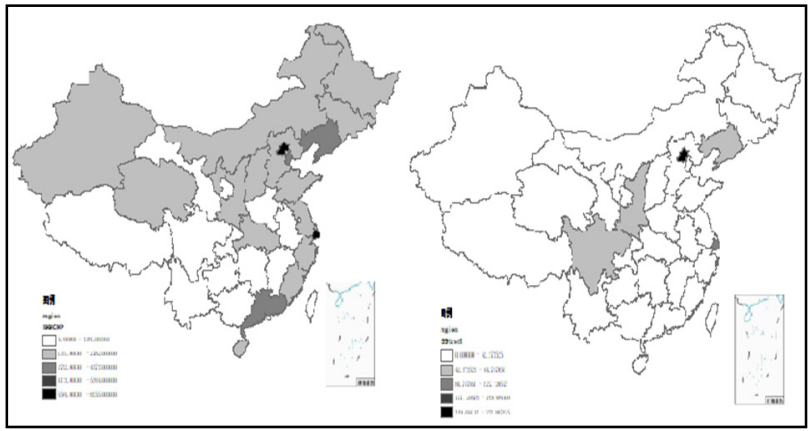

Fig. 1. Spatial distribution map of China's per capita GDP (left) and knowledge stock (right) in 1991.

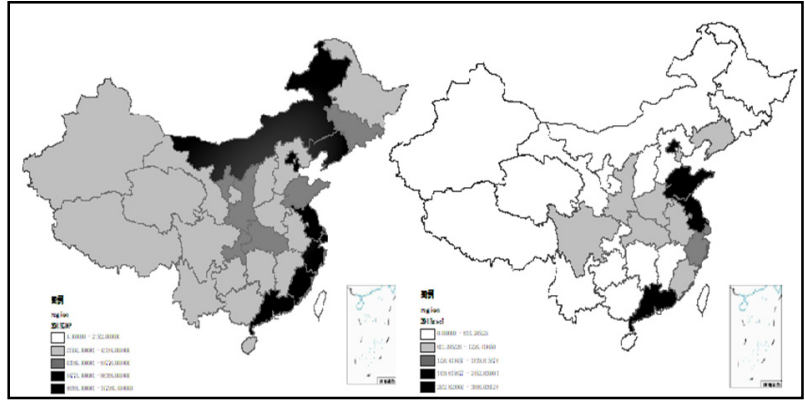

Fig. 2. Spatial distribution map of China's per capita GDP (left) and knowledge stock (right) in 2015.

The color in the figure changes from lighter to darker, indicating an increase in the number. On the whole, the spatial pattern of the distribution of my country's knowledge stock and per capita GDP from 1991 to 2015 showed the characteristics of eastward and southward agglomeration.

\subsection{Analysis on the Convergence of China's Provincial Regional Economic Growth}

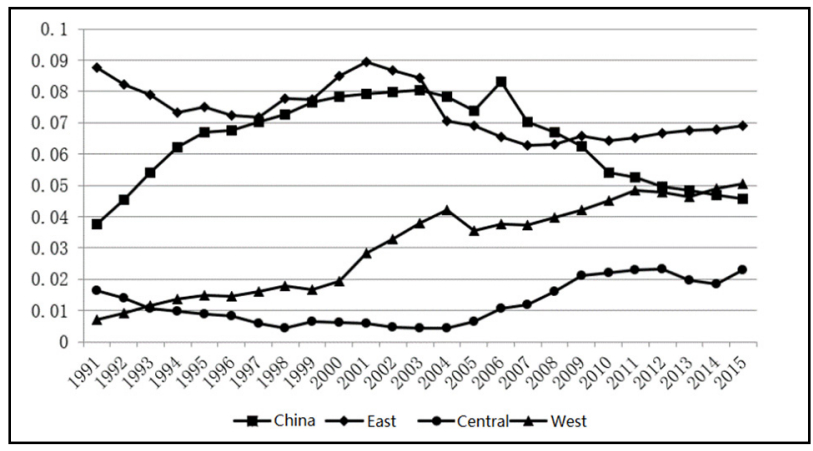

Fig. 3. Trend of Theil Index in China and the Three Major Regions.

The above figure shows that the provinces in the eastern region are showing convergence, but there is no club convergence within the central and western regions, and the economic growth gap within the region is gradually increasing from 1991 to 2015.

\subsection{Analysis of the Spatial Correlation of China's Regional Economy}

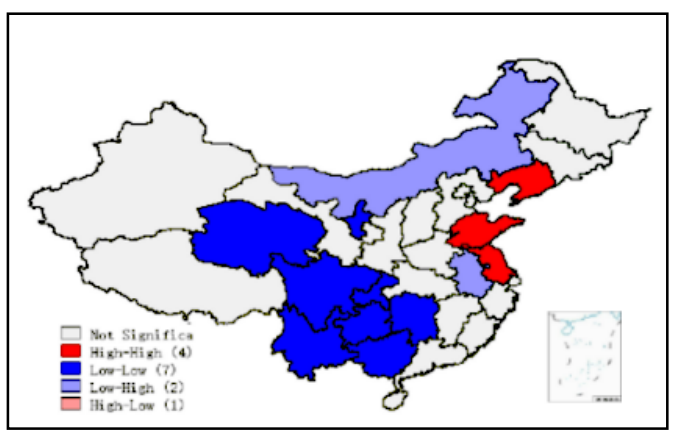

Fig. 4. LISA cluster chart of total GDP in 1991. 


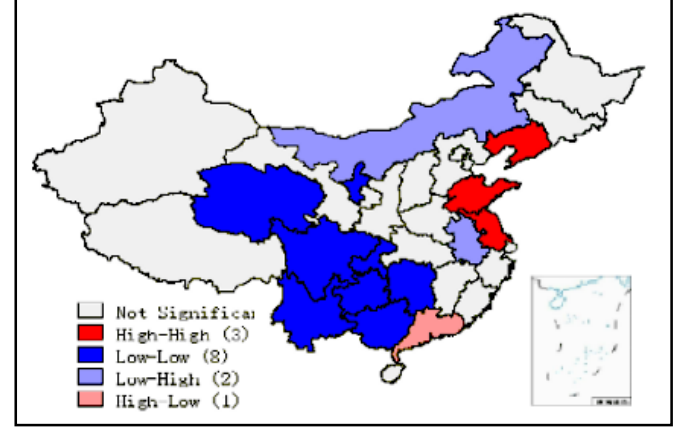

Fig. 5. LISA cluster chart of total GDP in 2015.

Using GeoDa to make the local spatial autocorrelation LISA cluster map of the GDP of each province and city in 1991 and 2015, the LISA cluster map can intuitively test the spatial interaction of the economic growth of China's provinces and cities.

As can be seen in the figure, the eastern region, which is in the high-high spatial agglomeration type, has obvious advantages in economic development, and the western region with underdeveloped economic development is in the low-low type. Through the analysis of the results obtained from the spatial autocorrelation test, there is indeed a more obvious "club phenomenon" in the development of China's regional economy.

\subsection{The effect of knowledge spillovers on the phenomenon of Chinese regional clubs}

Table 1. Variable introduction table.

\begin{tabular}{|c|c|}
\hline Variable & Variable Interpretation \\
\hline $\ln y_{i, t-1}(\beta)$ & GDP per capita \\
\hline $\ln \left(\sum_{i, j \neq 1} \xi_{j} K R_{j, t}\right)$ & Provincial knowledge spillovers \\
\hline $\ln \left(\sum_{i, j \neq 1} \xi_{j} K R_{j, t}\right)$ & FDI form of knowledge spillover \\
\hline $\ln \left(\sum_{i, j \neq 1} \xi_{j} K R_{j, t}\right)$ & Imported form of knowledge spillover \\
\hline $\ln K$ & Physical capital stock \\
\hline $\ln K R$ & Stock of intellectual capital \\
\hline $\ln U$ & Infrastructure \\
\hline $\ln F$ & Urbanization rate \\
\hline
\end{tabular}

Table 2. SDM model results for eastern and central regions

\begin{tabular}{|c|c|c|}
\hline Variable & Eastern & Central \\
\hline$w x-\ln y_{i, t-1}(\beta)$ & $\begin{array}{c}-0.314 \\
(0.0107)\end{array}$ & $\begin{array}{c}0.240^{* * *} \\
(0.0153)\end{array}$ \\
\hline$w x-\ln \left(\sum_{i, j \neq 1} \xi_{j} K R_{j, t}\right)$ & $\begin{array}{c}0.0057^{* *} \\
(0.0023)\end{array}$ & $\begin{array}{c}0.000152 \\
(0.00214)\end{array}$ \\
\hline$w x-\ln \left(F D I_{i, t}^{*} \sum_{j} R D_{j}\right)$ & $\begin{array}{c}0.00213 \\
(0.00408)\end{array}$ & $\begin{array}{c}0.00286 \\
(0.00892)\end{array}$ \\
\hline$w x-\ln \left(M_{i, t}^{*} \sum_{j} R D_{j}\right)$ & $\begin{array}{c}0.00340 \\
(0.00275)\end{array}$ & $\begin{array}{c}0.00428 \\
(0.00497)\end{array}$ \\
\hline$w x-\ln K$ & $\begin{array}{c}-0.00181 \\
(0.00222)\end{array}$ & $\begin{array}{c}0.00518 \\
(0.00476)\end{array}$ \\
\hline wx-lnKR & $\begin{array}{c}0.00915 \\
(0.00623)\end{array}$ & $\begin{array}{c}0.00931 \\
(0.0114)\end{array}$ \\
\hline R2 & 0.998 & 0.924 \\
\hline convergence speed $(\phi)$ & 0.0161 & 0.007 \\
\hline Hausman Test & $\begin{array}{c}19.09 \\
(0.0391)\end{array}$ & $\begin{array}{c}20.21 \\
(0.0273)\end{array}$ \\
\hline $\begin{array}{c}338.82 \\
(0.003)\end{array}$ & $\begin{array}{c}189.40 \\
(0.0000)\end{array}$ \\
\hline
\end{tabular}

Table 3. SDM model results for western and mixed eastern and central regions

\begin{tabular}{|c|c|c|}
\hline Variable & Western & $\begin{array}{c}\text { East and } \\
\text { Central }\end{array}$ \\
\hline$w x-\ln y_{i, t-1}(\beta)$ & $\begin{array}{c}-2.887 \\
(0.039)\end{array}$ & $\begin{array}{c}-0.296 \\
(0.000)\end{array}$ \\
\hline$w x-\ln \left(\sum_{i, j \neq 1} \xi_{j} K R_{j, t}\right)$ & $\begin{array}{c}0.0057^{* *} \\
(0.0023)\end{array}$ & $\begin{array}{c}-0.0107 \\
(0.00954)\end{array}$ \\
\hline$w x-\ln \left(F D I_{i, t}^{*} \sum_{j} R D_{j}\right)$ & $\begin{array}{c}0.00213 \\
(0.00408)\end{array}$ & $\begin{array}{c}-0.000495 \\
(0.00349)\end{array}$ \\
\hline$w x-\ln \left(M_{i, t}^{*} \sum_{j} R D_{j}\right)$ & $\begin{array}{c}0.00340 \\
(0.00275)\end{array}$ & $\begin{array}{c}-0.00447 \\
(0.00506)\end{array}$ \\
\hline$w x-\ln K$ & $\begin{array}{c}-0.00181 \\
(0.00222)\end{array}$ & $\begin{array}{c}0.00567 * * * \\
(0.00212)\end{array}$ \\
\hline wx-lnKR & $\begin{array}{c}0.00915 \\
(0.00623)\end{array}$ & $\begin{array}{c}0.0337^{* * *} \\
(0.0129)\end{array}$ \\
\hline R2 & 0.998 & 0.99 \\
\hline convergence speed $(\phi)$ & 0.0161 & -0.002 \\
\hline Hausman Test & $\begin{array}{c}19.09 \\
(0.0391)\end{array}$ & $\begin{array}{c}109.53 \\
(0.000)\end{array}$ \\
\hline LR Test & $\begin{array}{c}338.82 \\
(0.003)\end{array}$ & $\begin{array}{c}159.48 \\
(0.0000)\end{array}$ \\
\hline p $01 *$ p $<0.05, * \mathrm{p}<0.1$ & & \\
\hline
\end{tabular}

The variables in Table 1 are the introduction of variables used in the spatial measurement model of this article.

Club convergence means that provinces with similar economic structures and similar initial economic 
conditions are regarded as members of a club. Within each club with different economic levels, the gap in the level of economic growth of each province decreases. In order to examine the influence of knowledge spillover factors on the convergence of Chinese clubs, the following will use data from the eastern, central and western regions of China to conduct investigations.

The selection of the three regional spatial dynamic panel models in Table 2 and Table 3 has been tested by the Lagrangian multiplier (LR), and the spatial Dubin model (SDM) is selected for model estimation, and Hausman test (Hausman) The results also significantly rejected the null hypothesis through the test. After these two tests, this paper determined the final model-SDM fixed-effects model.

From the results of the spatial Dubin model regression, there is significant club convergence in the eastern and central regions, but there is no club convergence in the western region. This is different from the estimation results in the ordinary dynamic panel. The results of the ordinary dynamic panel estimation have obvious club convergence in the eastern and western regions, but there is no club convergence in the central regional economy. After adding spatial considerations, this paper finds that the knowledge spillover in neighboring regions is positively correlated with the economic growth and convergence of the eastern and central regions, but negatively correlated with the economic growth and convergence of the western, eastern, and central regions without club convergence. It just shows that knowledge spillovers in neighboring regions can promote regional economic growth and club convergence. Only by absorbing and learning the technology diffusion and spillover effects of neighboring advanced regions can backward regions promote regional economic growth and achieve convergence with developed regions' economic levels. In addition, we found that in ordinary dynamic panels that do not consider spatial effects, many explanatory variables are not significant, but in the spatial Dubin model, the effects of these explanatory variables on regional economic growth and convergence become significant and sufficient. It shows that after considering the spatial factors, some biases in the regression estimation will be avoided. Finally, although the eastern and central regions have their own club convergence within the region, the estimation results of the central and eastern regions show that the economies of the two regions are characterized by divergence, which also shows that the gap in technology and knowledge will cause The gap in the degree of economic development between regions, only by actively absorbing technology diffusion and transfer from developed regions can backward regions truly catch up with developed regions.

\section{Conclusions}

This paper focuses on the convergence brought about by the regional economic development driving factors whose main influencing factor is the diffusion of knowledge spillover technology. The spatial Dubin model basically confirms that technology spillovers between provinces will significantly promote the economic convergence of the provinces in the region. Scientific research and experimental development (R\&D), foreign direct investment (FDI) and import trade (M) in China's three major regions all have significant spatial spillover effects, which affect the rate of convergence of economic growth in various provinces in the region to varying degrees. Although the speed of convergence within the three major regions is uneven, it is basically consistent with the level of regional economic development. From east to west, it gradually slows down. This is because the innovation activities and innovation exchanges between the provinces in the eastern region are active, the flow of scientific and technological innovation talents is frequent, and the innovation efficiency is relatively high. Although the national strategy of the rise of the central region and the development of the western region has greatly promoted the development of the central and western regions, due to the weak foundation of technological innovation and the limitation of economic strength, transportation constraints, limited investment in technological innovation and a poor innovation environment Good, the lack of attractiveness for highlevel talents leads to low innovation efficiency and restricts the economic development of the central and western regions.

\section{Acknowledgements}

This study is partly sponsored by the project establishment and Practice of Cloud-based ERP Simulation Teaching Innovation Scheme" (201801024009) of the Ministry of Education; and Philosophy and Social Science Project of Guangdong Province (GD16CGL07), "Research on Enterprise Innovation in the Process of Agglomeration of the Electronic Industry in the Pearl River Delta".

\section{References}

1. Shen, K., and J. Ma . "The Characteristics of "Club Convergence" of China's Economic Growth and Its Cause." Economic Research Journal, (2002)

2. Galor O . Convergence: Inferences from Theoretical Models. J. Working Papers, (1996)

3. Romer M , Romer P M . Endogenous technological change. J. Nber Working Papers. 98:71-102(1989)

4. Gallo J , Ertur C . Exploratory spatial data analysis of the distribution of regional per capita GDP in Europe, 1980-1995. J. Papers in Regional Science.82:175201(2003)

5. Griliches Z . Hybrid Corn: An Exploration in the Economics of Technological Change. J. Econometrica, 25:501-522 (1957) 